\title{
Study of the phenomenon of frailty of the Bead (MOLE) in the manufacture of bicycle tyres
}

\section{Jerfeson de Barros Soprano ${ }^{1}$, José Antonio da Silva Souza²}

\begin{abstract}
1,2 Programa de Pós-Graduação em Engenharia de Processos do Instituto de Tecnologia da Universidade Federal do Pará (PPGEP/ITECUFPA). Bairro Guamá. CEP: 66075-110. Caixa Postal 479. PABX +55 913201 7000. Belém - Pará - Brasil
\end{abstract}

Email: jerfeson.bsoprano@gmail.com, jass@ufpa.br.

Received: October $11^{\text {th }}, 2018$

Accepted: November $01^{\text {th }}, 2019$

Published: March $31^{\text {th }}, 2019$

Copyright (02016 by authors and Institute of Technology Galileo of Amazon (ITEGAM).

This work is licensed under the Creative Commons Attribution International

License (CC BY 4.0).

\section{ABSTRACT}

Over the years the tyre has evolved gradually and with this every day gains new shapes and models. However, even with all technology and evolution in the machines that produce it in the company Levorin, is happening a phenomenon called Mole bead. Thus, the present research was developed with the purpose of identifying the possible causes that are generating the defect of the soft bead, in the production line of the factory where bicycle tires are made, aiming to eliminate the defect (s) and how Consequences stop wasting materials, time and manpower. The efficacy of the research was assessed through participatory research and application of a questionnaire. With this research it was possible to perceive that the problem of the soft bead phenomenon occurred due to a misalignment (height and width) in the bases where the chestnuts are fixed. There was also a lack of regulators to fix housing adjustment. And the preconformator chestnuts were also not compatible with their measurement. Thus, the alignments of the chestnuts arms, the production of chestnuts with dimensional by measure and the manufacture of regulators were performed.

Keywords: Tires, Processes, Mole bead.

\section{Estudo do fenômeno de fragilidade do talão (talão mole) na fabricação de pneu de bicicleta}

\begin{abstract}
RESUMO
Ao longo dos anos o pneu vem evoluindo de forma gradativa e com isso a cada dia ganha novas formas e modelos. Entretanto, mesmo com toda tecnologia e evolução nas máquinas que o produzem na empresa Levorin, está acontecendo um fenômeno chamado Talão Mole. Desta forma, a presente pesquisa foi desenvolvida com o propósito de Identificar as possíveis causas que estão gerando o defeito do talão mole, na linha de produção da fábrica onde são confeccionados pneus de bicicletas, visando eliminar o(s) defeito(s) e como consequências deixar de desperdiçar materiais, tempo e mão de obra. A eficácia da pesquisa foi avaliada através de uma pesquisa participativa e aplicação de questionário. Com a presente pesquisa foi possível perceber que o problema do fenômeno de talão mole ocorria em decorrência de um desalinhamento (altura e largura) nas bases onde são fixadas as castanhas. Também havia uma falta de reguladores para fixar a regulagem de acomodação da carcaça. E as castanhas do Pré-Conformador também não eram compatíveis com a sua medida. Dessa forma, foram realizados os Alinhamentos dos Braços das Castanhas, a Confecção de Castanhas com dimensional por medida e Confecção de reguladores.
\end{abstract}

Palavras-Chave: Pneus, Processos, Talão Mole.

\section{INTRODUÇÃO}

Sabe-se que a modernização chegou a vida de todos. É uma questão de necessidade. No tocante a isto, pode-se destacar a evolução do uso do pneu. Hoje ele se encontra muito mais presente em nossas vidas, tornando bem maior a sua utilidade, bem como também uma grande preocupação com o seu descarte. [1].

Com o passar dos anos as empresas fabricantes de pneus começaram a investir em equipamentos mais modernos e novas tecnologias. De acordo com a [2], essa nova visão sobre a importância do conforto e mais modernização nos pneus, se deu 
com Robert W. Thompson, o qual era um engenheiro, e foi considerado o criador do primeiro pneu de borracha inflado com ar. Sua invenção se deu a partir da década de 1930, a partir de então a evolução dos pneus não parou mais de acontecer. Anos mais tarde nascia o primeiro inforu de borracha sintético. Começava aí uma nova concepção e uma feroz mudança sobre o universo dos pneus [3].

Uma década depois, a mesma BF Goodrich, lança o primeiro pneu sem câmara, mais uma revolução para o mercado. Nos anos seguintes, o pneu continuou evoluindo ganhando novas formas e tecnologias - com aperfeiçoamentos em seu desempenho, mais resistência devido ao impacto com o solo e também em suas rodagens. De acordo com a empresa [4], o pneu tornou-se item indispensável na vida cotidiana dos seres humanos, pois é algo indispensável para a logística em geral. Hoje seus fabricantes procuram a cada dia melhorar suas produções produzindo um produto com maior segurança, conforto e durabilidade.

Sobre essa perspectiva, [5], apresenta um pensamento bastante pertinente. Segundo a autora "tanta modernidade trouxe um problema para o meio ambiente. Ao longo dos tempos, encontrar uma destinação correta para pneus usados e seus componentes se tornou algo imprescindível para colaboração da preservação ambiental". De acordo com dados de [6], "estimativas indicavam que são gerados 35 milhões de carcaças de pneus anualmente; e que existem mais de 100 milhões de pneus abandonados em todo o país".

Pensando nisso, algumas empresas fabricantes de pneus oferecem várias opções de reaproveitamento para solucionar esse problema. Segundo [7], hoje já existem, recapagem, recauchutagem e remoldagem. Todos estes processos são já são realizados no Brasil, seguindo o mesmo padrão de reforma dos EUA e dos países mais desenvolvidos da Europa. Segundo afirma a ABR2 (Associação Brasileira de Recauchutadores, Reformadores e Remoldadores de Pneus), reformar pneus é uma opção econômica, segura e ecologicamente correta. Portanto, deveria ser mais utilizada pelos órgãos públicos.

Dessa forma, percebe-se o quão complexo é o processo de fabricação e modernização de um pneu, pois, envolve alta tecnologia e várias etapas, pois o mesmo possui vários tipos de materiais e compostos de borracha para otimizar sua performance.

Sob esse viés, mesmo com toda a tecnologia utilizada nos pneus da empresa aqui pesquisada, foi identificado uma alteração no sistema de produção dos pneus, aqui denominado "Fenômeno de Talão Mole", o qual está prejudicado a produção dos mesmos.

A seguir é apresentado o conceito de Talão Mole. A saber:

\section{CONCEITO DE TALÃO MOLE}

É um fenômeno que se caracteriza pelo deslocamento descentragem do talão em parte da sua circunferência em um ou dois lados do talão. Dessa forma, a sustentação do talão não acontece, pois, a região dos pneus fica flexível, o que gera o defeito nos pneus [8] (Levorin, 2017).

\section{II.1 A GESTAO DE PESSOAS, OS PROCESSOS E A QUALIDADE NA PRODUÇAO DE PNEUS DE BICICLETAS.}

Todo e qualquer produto que é posto à venda, precisa e deve ser de qualidade. Reportando-nos a produção de pneus, esta não poderia ser diferente. Aqui a atenção, preocupação, e bom senso, são essenciais para um resultado satisfatório tanto do produtor como do cliente, neste sentido, pode-se dizer que a mão de obra se faz essencial para o resultado final.

Hoje as empresas visão encontrar funcionários multifacetados, ou seja, aqueles que se envolvem e se entregam ao processo de forma arrojada, com censo de liderança, motivadores. Que ajudam aos colegas de trabalho a sentirem-se capazes de participar do processo produtivo da empresa de forma ativa do início ao fim.

[9], apresentam uma visão bastante pertinente quanto a isso ao afirmar que: "Com o aumento do uso dos recursos tecnológicos e com o forte movimento para "que tudo saia da melhor forma" com eficiência e eficácia, as organizações não estão buscando mais profissionais que apenas desempenhem bem uma função, querem um funcionário que possa agregar valor e que tenha espírito de equipe, ou seja, que se relacione bem com outros colaboradores". Assim, um dos grandes desafios dos gestores nas organizações da atualidade é gerir negócios que possam ir além dos resultados e dos lucros. Essa evolução e a mudança de pensamento não acontecem apenas em relação aos setores de trabalho e às atividades desempenhadas em si, mas também na gestão que valoriza os colaboradores.

Sabe-se que o poder de liderança é um fator mais que mobilizador dentro de qualquer ambiente. Principalmente em se tratando de trabalho organizacional. Pessoas que são capazes de realizar várias atividades e que estejam realizadas com excelência, elevam o crescimento de qualquer indústria. Hoje o que mais se prioriza são funcionários que se envolvem no processo, bem como motivam os colegas a se sentirem capazes de fazer o mesmo. Pessoas assim, são fundamentais para o bom andamento do serviço e da qualidade de tudo aquilo que é produzido pelo aquele setor da empresa.

$\mathrm{Na}$ visão do autor supracitado, as empresas que só visam lucro, produção e redução de gastos, sem se preocupar com as pessoas, para além de suas funções e de seus trabalhos, perdem em planejamento, em comunicação e o principal: em motivação profissional. Hoje as organizações que conquistam sucesso são as que valorizam a qualidade dos trabalhos e apresentam ações voltadas para a motivação e satisfação dos colaboradores.

Considerando este contexto, neste capitulo será apresentado, e discutido a importância da qualidade de um produto e o formato de como acontecem os processos de produção dos pneus de bicicletas dentro num sistema organizacional.

Nesse contexto [10], comenta que "em muitas organizações falava-se, até pouco tempo, em "relações industriais", uma espécie de visão burocratizada que vem desde o final da revolução industrial e que encontrou seu auge na década de 1950, época marcada pelo grande desenvolvimento do Brasil e período de transição das guerras mundiais". Em outras organizações fala-se em administração de recursos humanos, uma visão mais dinâmica que predominou até 1990 e foi adotada por algumas empresas mais sofisticadas em administração de pessoas, que tendiam a considerar sim o ser humano como dotado de habilidades e capacidades intelectuais".

Desde muito tempo atrás que as relações entre empregador e empregado vem tentando se estreitar para um melhor resultado entre beneficiador e beneficiado. Sem a justificativa de que os fins justificam os meios, todos os envolvidos nesse processo de industrialização de produtos, buscam, no final, o melhor resultado que é o produto de qualidade. Assim, busca-se qualificar a mão de obra para que os rendimentos sejam cada dia maiores. Empregados que tenham 
características de liderança são fundamentais para o sucesso do negócio.

O retorno e o desenvolvimento das atividades diárias se alteram quando a satisfação dos mesmos se modifica. Se as pessoas se sentem recompensadas, o trabalho tende a sair de uma forma melhor. Na visão [11], "uma das melhores formas de desenvolvimento de pessoas na organização é o treinamento, processo de ensinamento para os colaboradores para o bom desempenho das ferramentas utilizadas nas atividades. Para empresas de comunicação, um bom treinamento é aquele relacionado ao atendimento ao público. Os profissionais de comunicação têm como ponto forte de suas atividades a forma de se comunicar com seus públicos. As mensagens devem ser claras e concisas já que, sem essas características, elas podem gerar duplos sentidos e alterar os processos de trabalho".

Os investimentos na qualificação profissional são altamente importantes para o bom andamento do processo de produção dentro de uma empresa. Assim como uma boa comunicação dentro do grupo. Os processos industriais são importantes assim como a boa relação entre os funcionários e clientes. Pessoas que tem facilidade de se comunicar e se relacionar com o público são tidas como lideres natos pelos colegas de trabalho.

\section{METODOLOGIA}

Nesta pesquisa foram utilizados como instrumentos de coleta de dados:

1- Levantamento bibliográfico realizado através de livros e artigos científicos como forma de dar mais sustentação teórica a esta pesquisa.

Também foi realizado uma observação participante, nos dias 01 , 02, 03, 04, 05, 06, 07 do mês de Abril e nos dias 24, 25, 26, 27 , 2829 e 30 de maio de 2018, em diferentes horários, na máquina de confecção da carcaça e no processo de vulcanização dos pneus. Nesse momento foi possível conversar com os funcionários e analisar sobre os possíveis motivos para essas falhas estarem acontecendo.

2- Aplicação de Questionário (criado pelo próprio pesquisador), junto ao supervisor de produção responsável pela linha de produção e aos outros funcionários que também trabalham nesta mesma linha, nos turnos da manhã, tarde e noite com o intuito de descobrir quais as causas do problema em questão.

3- Diagrama de Ishikawa (princípios de causas e efeitos).

4- E por fim, foi proposto ideias e soluções utilizando a ferramenta $5 \mathrm{~W} 2 \mathrm{H}$ para o problema em questão.

\section{III.1 JUSTIFICATIVA DA DEMANDA}

Com a demanda em alta na fabricação de pneu de bicicleta, devido às pessoas procurarem outras opções de deslocamento, tanto para fugir do transito das grandes cidades como por uma questão de saúde, o aumento significativo na produção de pneus de bicicletas só cresceu no país nos últimos anos. Porém, um fenômeno chamado "Talão Mole" está ocorrendo na linha de produção da empresa Levorin, o que está causando vários transtornos.

Dessa forma, surgiu a necessidade da realização desta pesquisa para tentar descobrir o "Porque e Como" este fenômeno vem acontecendo. No gráfico da Figura 1 é possível perceber que o número de refugo só tem crescido na linha de produção da empresa aqui pesquisada, o qual não permite que as metas estabelecidas sejam cumpridas, gerando assim um grande transtorno, pois, os pneus produzidos não são aceitos pelos requisitos internos do padrão de qualidade da empresa. Assim, esses pneus são descartados gerando desperdícios de materiais, tempo, mão de obra, elevando o custo do produto, e ainda coloca em risco até mesmo a entrega dentro do prazo do produto para o cliente.

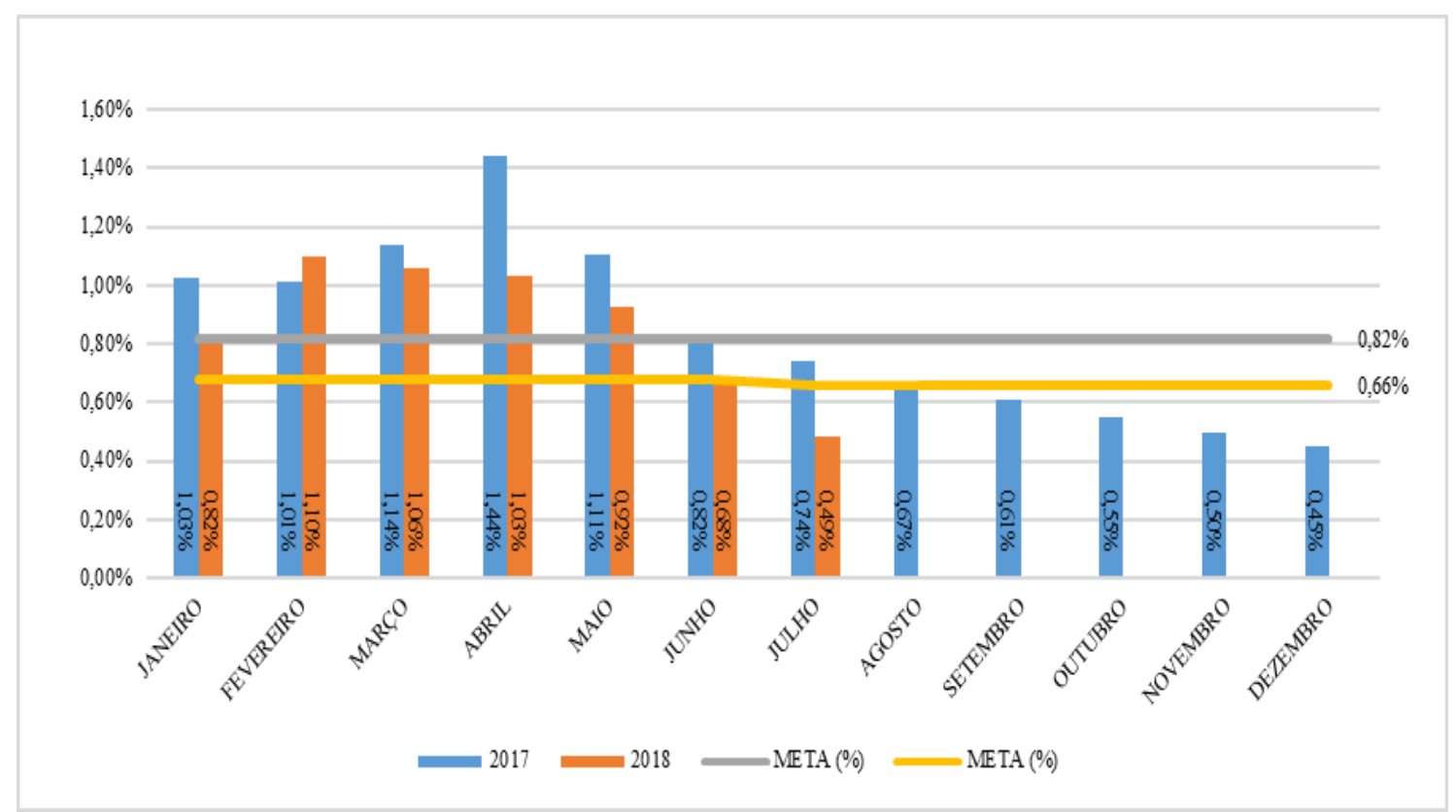

Figura 1- Demonstrativo com defeito de Talão Mole. Fonte: Levorin (2017-2018).

\section{III.2 PROBLEMA DA PESQUISA}

No processo de fabricação do pneu de bicicleta estava ocorrendo um defeito chamado de talão mole, onde através de observações e com o auxílio do Diagrama de Ishikawa (princípio de causa e efeito), foi verificado Onde, Como e em Qual momento este defeito ocorria e como consequência criar medidas para solução deste problema. 


\section{RESULTADOS E DISCUSSÃO}

\section{IV.1 COMPOSIÇAO QUÍMICA DOS PNEUS}

Os componentes utilizados para a fabricação da borracha necessária à produção de pneus têm uma mistura de borracha sintética, borracha natural, óleos, enxofre, negro de fumo, óxido de zinco, entre outros componentes.

Tabela 1 - Componentes do Pneu.

\begin{tabular}{|c|c|c|}
\hline Material & Pneu Ligeiro & Pneu Pesado \\
\hline Borracha & $47 \%$ & $45 \%$ \\
\hline Negro de Fumo & $21,5 \%$ & $22 \%$ \\
\hline Aço & $16,5 \%$ & $25 \%$ \\
\hline Têxtil & $5,5 \%$ & -- \\
\hline Óxido de Zinco & $1 \%$ & $2 \%$ \\
\hline Enxofre & $1 \%$ & $1 \%$ \\
\hline Aditivos & $7,5 \%$ & $5 \%$ \\
\hline
\end{tabular}

Fonte: Histórico Empresa Levorin (2018).

\section{IV.2 INDUSTRIA DE PNEUS NO BRASIL}

São as empresas de grande porte que realizam a produção de pneus no Brasil e no mundo. Neste contexto, sua atividade pode assumir todas as etapas da combinação das matérias primas, como borracha natural, derivados do petróleo, aço, produtos químicos e têxtil.

É aqui onde todo o processo de industrialização do pneu acontece. Aqui são empregadas toda uma tecnologia de ponta para que pneus de diversos tamanhos e tipos para que assim, possam atender toda uma demanda de mercado. Esse mercado vem crescendo a cada dia, aja visto que a procura é sempre muito grande e muito ativa. "Com um consumo de 72, 6 milhões de unidades em 2013, resultado próximo ao recorde de 73 milhões obtidos em 2010, o país destinou 13,6 milhões de unidade da produção para exportação" [12].

Para melhor compreensão do problema aqui pesquisado, será apresentado o (passo a passo) de como ocorre todo o processo de fabricação dos pneus de bicicleta da empresa para que seja possível compreender de que forma ele se configura.
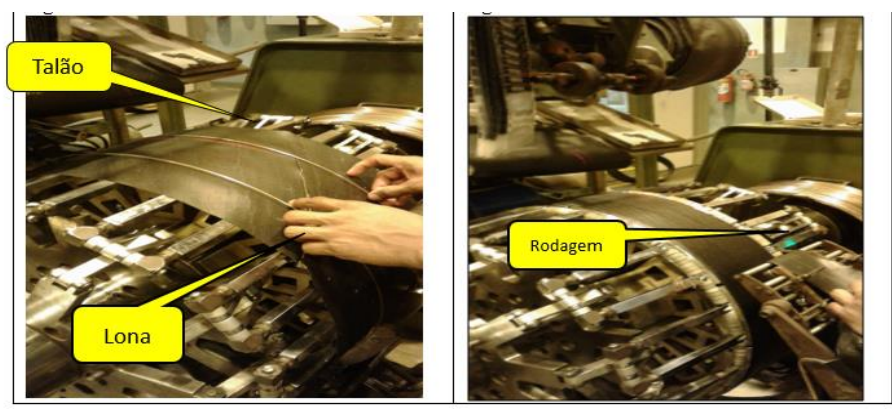

Figura 2- Confecção da Carcaça.

Fonte: Autores (2018).

Esta etapa é de extrema importância, pois, este processo é manual e precisa de muita atenção e habilidade da mão de obra do operador. Este precisa estar sempre atento a centralização e o posicionamento correto do talão, pois, caso aja desatenção haverá um deslocamento e após a vulcanização aparecerá uma não conformidade (defeito de talão) no pneu, o que pode gerar desperdício de matéria prima, tempo e mão de obra.

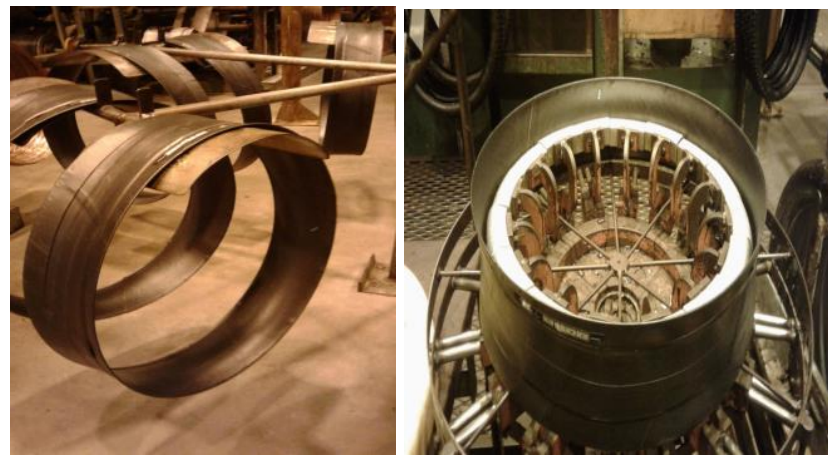

Figura 3: a) Carcaça pronta b) Pré- Conformador Fonte: Autores (2018).

Na figura 3 é possível perceber que após a carcaça pronta, ela é posicionada em um dispositivo, onde o operador aciona um botão que exerce uma pressão sobre a mesma criando uma área e um formato que receberá a bexiga.

Após é apresenta a etapa de Conformação. Nesta fase o pneu ganha forma com a pressão exercida sobre ele, e este já recebe a bexiga dentro da carcaça, finalizando mais uma etapa do processo.

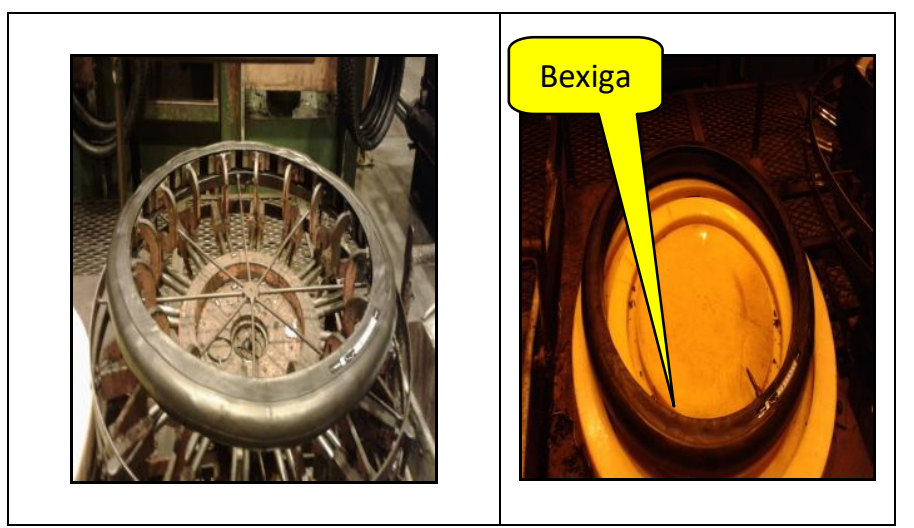

Figura 4: a) Recebe a pressão b) Recebe a bexiga Fonte: Autores (2018).

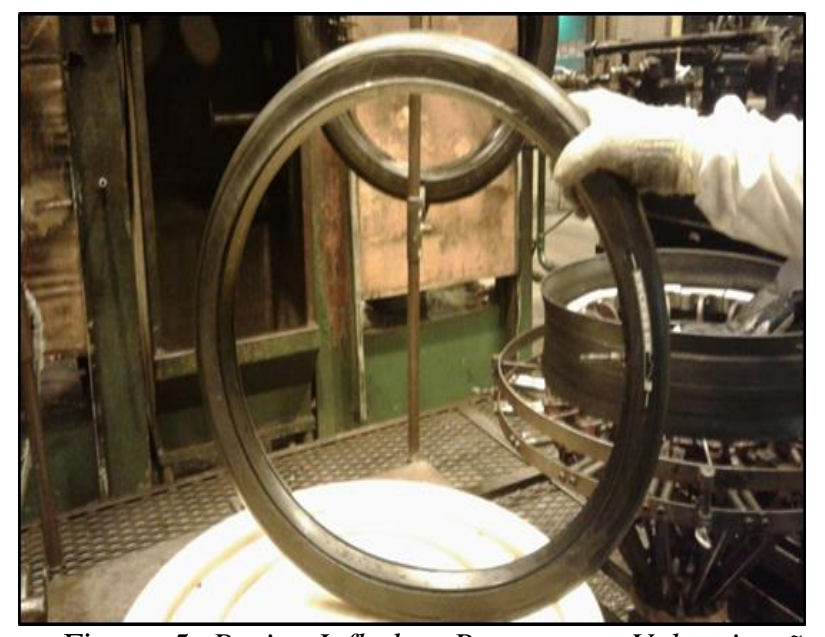

Figura: 5- Bexiga Inflada - Pronta para Vulcanização Fonte: Autores (2018).

Após essas etapas é a hora do processo de vulcanização. Esse processo é importantíssimo, pois, através dele a borracha (matéria prima) vai ser transformada em uma temperatura altíssima 180 graus, para que assim o pneu possa ser finalizado. 


\section{IV.3 VULCANIZAÇÃO}

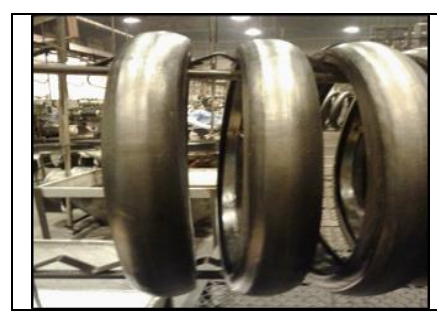

Figura 5- Posição da

Bexiga na Carcaça

Fonte: Autores (2018).

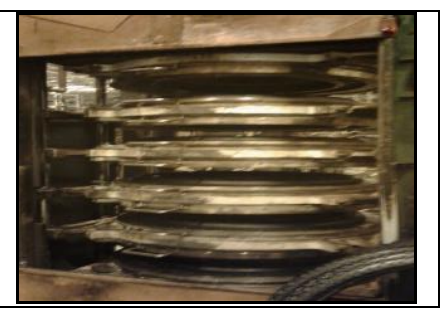

Figura 6 - Posição na

Prensa e Vulcanização

Fonte: Autores (2018).
Ao termino de todo esse processo, vem uma etapa de extrema importância. É a análise do produto, ou seja, é realizado uma inspeção sobre todo o pneu para verificar se o mesmo foi produzido de forma perfeita ou se está com algum defeito.

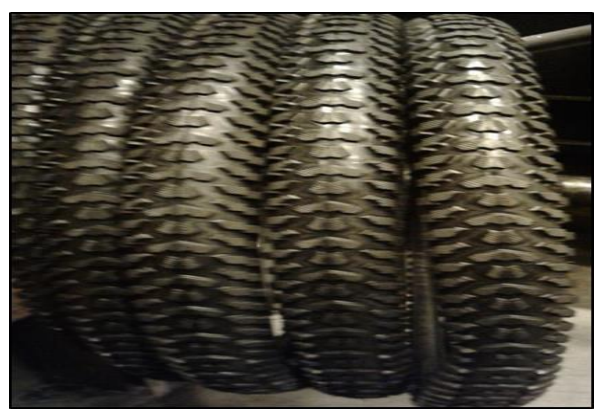

Figura 7 - Pneu da Bicicleta Pronto

Fonte: Autores (2018).

Dentro da empresa aqui pesquisada existe um setor interno chamado "Garantia da Qualidade" que foi criado para garantir que os requisitos internos sejam atendidos com base nas normas regulamentadoras preconizadas pelo Imetro e pelas normas da própria empresa, como forma de garantir ainda mais qualidade do produto, para satisfazer a necessidade do cliente, criando maior conforto, durabilidade e confiança nos produtos.

Abaixo é apresentado uma amostra da verificação de conformidade e a outra um pneu que foi reprovado com o defeito de talão mole.

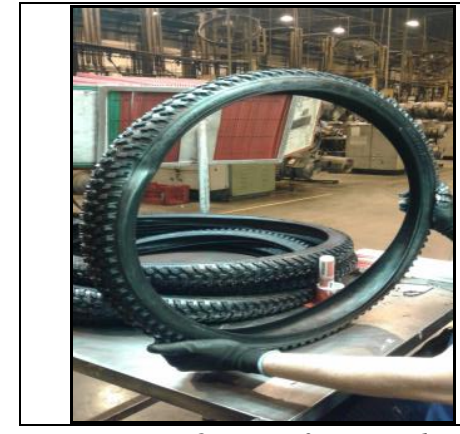

Figura 8 - Verificação de conformidade

Fonte: Autores (2018).

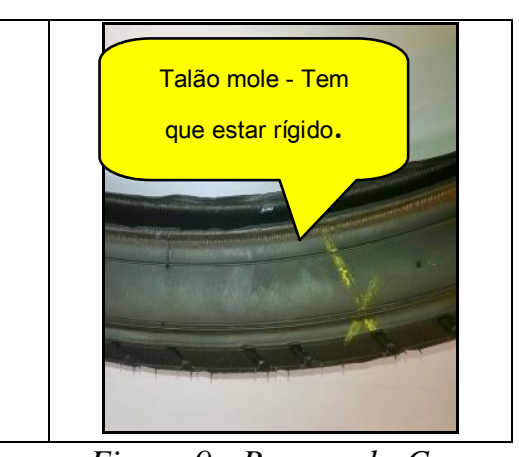

Figura 9 - Reprovado-Com talão Mole
Com todas as etapas finalizadas, os pneus estão prontos para serem encaminhados aos seus respectivos fornecedores e compradores. Porém, percebeu-se que na figura 9 o pneu apresentou o defeito ou fenômeno do talão mole. Sendo este o objeto deste estudo.

Assim, este trabalho visou identificar os motivos que estavam causando esse problema na produção dos pneus da empresa aqui pesquisada (durante duas semanas) para posterior encontrar as possíveis soluções e-ou sugestões eliminar tal fenômeno.

Com a aplicação do questionário foi possível analisar alguns pontos importantes sobre o fenômeno de Talão mole ocorrido na empresa. Abaixo é possível verificar a quantidade de pneus que saem com esse defeito diariamente. Notou-se que o problema em questão causa um transtorno e um prejuízo muito grande, em média a fábrica tem uma perca acima de 80 pneus diário e 2.400 pneus-refugo-mês.

Figura 10 - Qual a média de produção dos pneus- Dia.

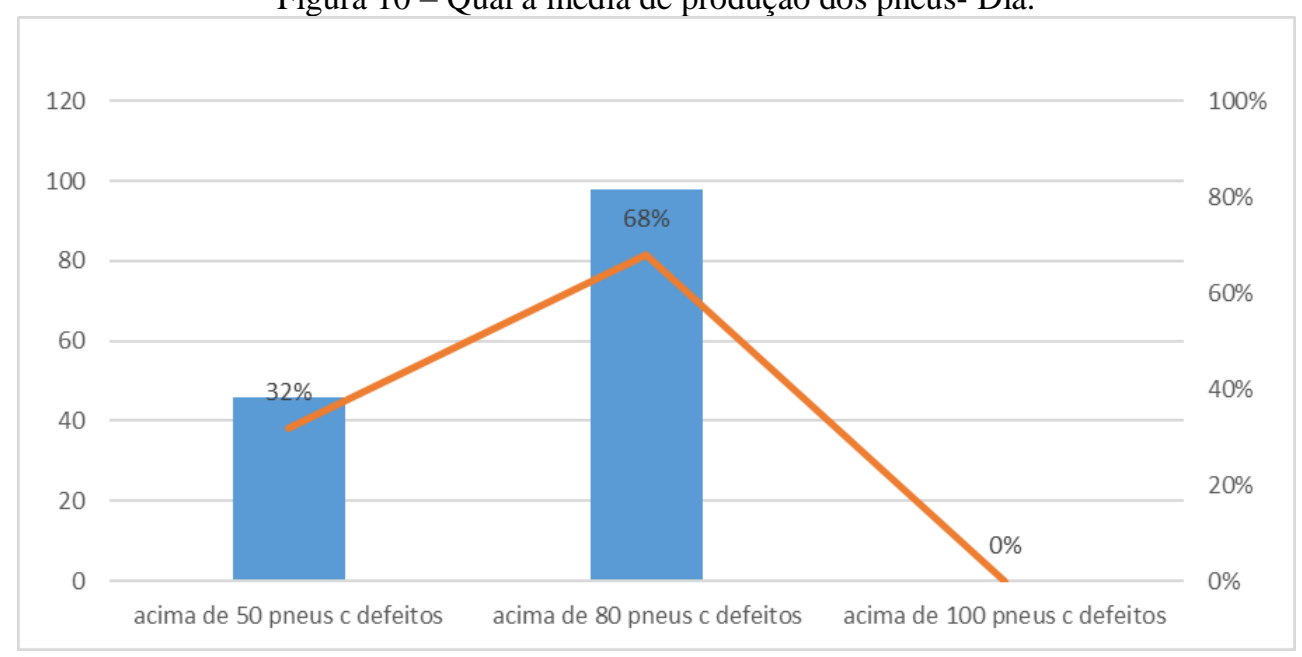

Fonte: Autores (2018).

O pesquisador também questionou junto ao supervisor (de acordo com os dados da empresa), sobre a média de produção por turno. Evidenciou-se que o turno matutino é o mais produtivo, pois, é o turno que mais tem funcionários. Neste turno a média de produção chega a 8.000 mil reais, mas sem este problema a produção poderia chegar a 12 mil. Entretanto, é o turno que mais apresenta o problema de talão mole. Por isso, é importante pensar em medidas como um Chek List para que todo colaborador (responsável pelas maquinas), faça uma avaliação antes do começo da atividade diária, visando assim, a diminuição do problema. 
Soprano and Souza, ITEGAM-JETIA. Vol. 05, No 17, pp 102-108. March, 2019.

Figura 11- Qual a média de produção de cada turno?

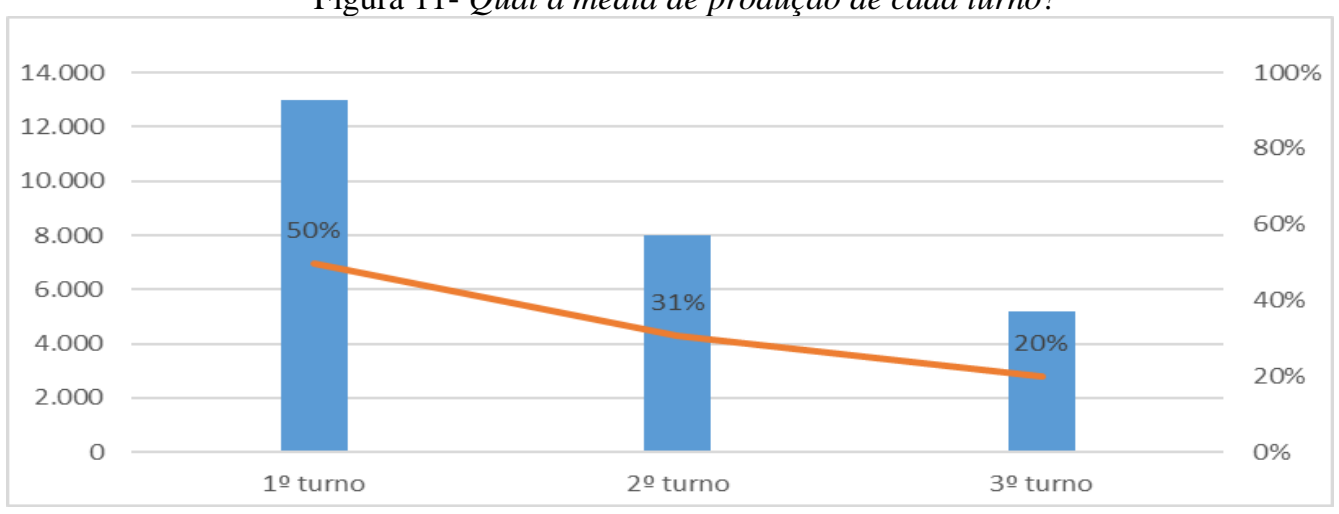

Fonte: Autores (2018).

Os operadores de produção também formam questionados sobre a forma de confecção, conformação e vulcanização podem estar influenciando no defeito do Talão Mole. Na visão deles, "Sim! É possível, pois, na confeccionadora temos dificuldades para alinhar-centralizar o talão no canal das castanhas, tendo em vista que os imãs estão com muitas folgas e tortos, ou seja, estão desalinhados. Já no Pré Conformador, temos castanhas altas e baixas; a pressão é muito forte chegando a danificar a carcaça em alguns momentos da operação, para isso é precisa do auxílio da manutenção para a regulagem desse equipamento". (Vide gráfico 09).

Gráfico 12 -A forma de confeccionar uma carcaça, conformar e vulcanizar podem estar influenciando no defeito de Talão Mole?

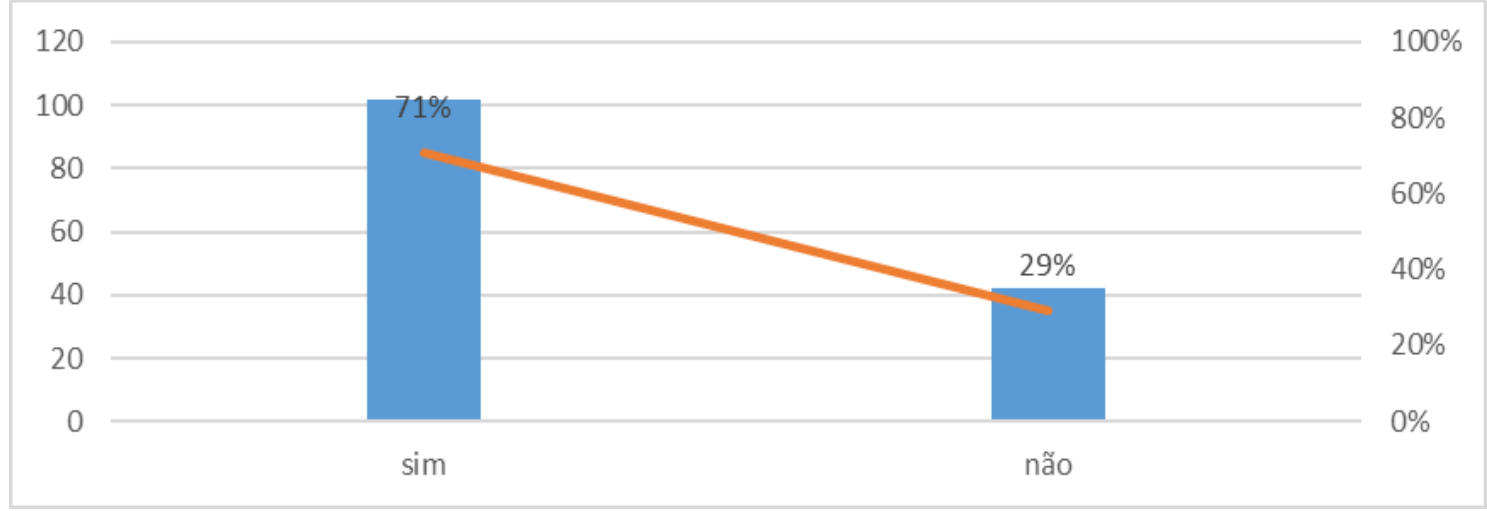

Fonte: Autores (2018).

IV.4 MÉTODO DE ICHIKAWA

A seguir são apresentados os benefícios a partir da aplicação do diagrama de causas e efeitos.

Figura 13 -Diagrama de causas e Efeitos

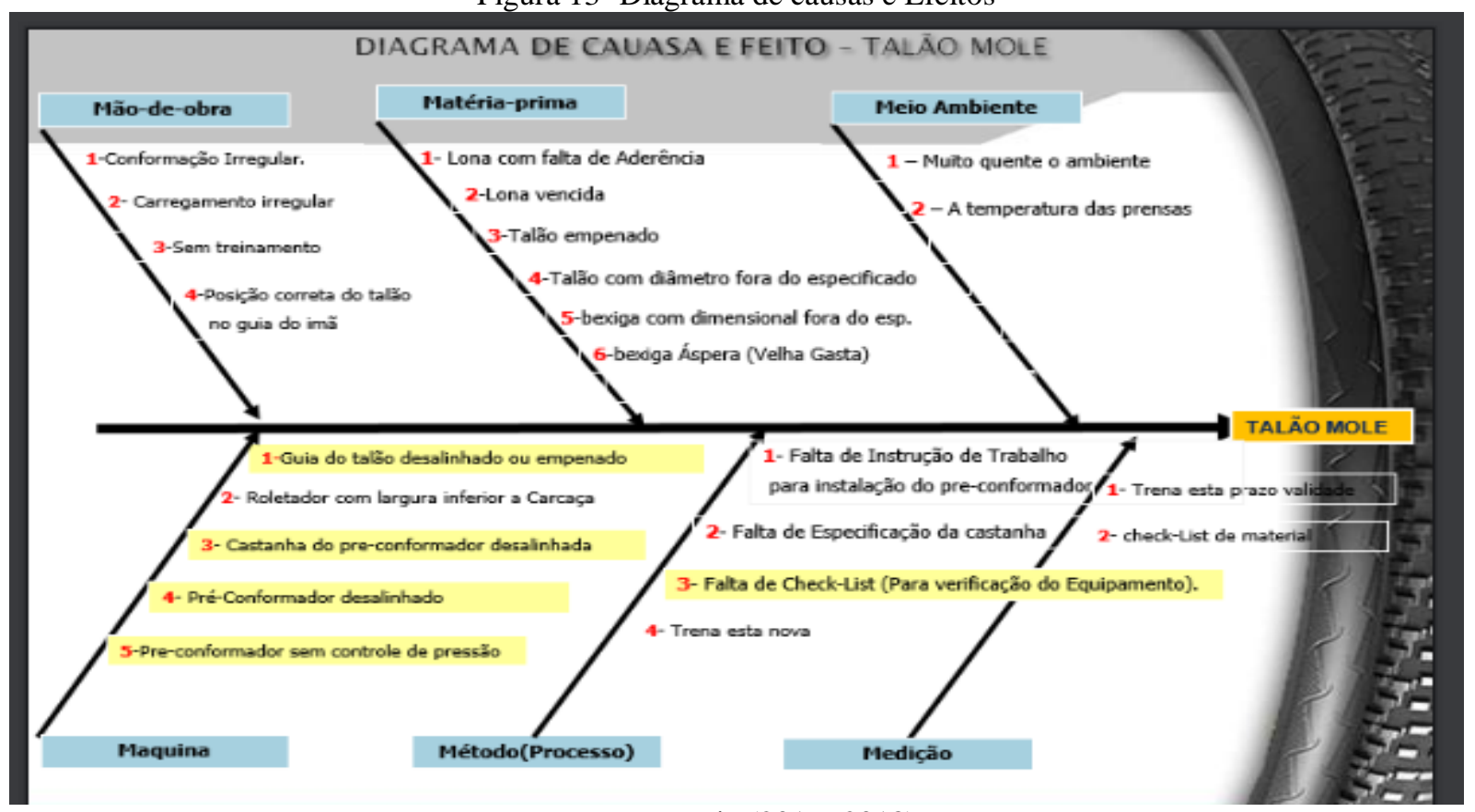

Fonte: Levorin (2017- 2018). 


\section{IV.5 MELHORIAS NO PROCESSO DE PNEUMATICO}

Com esta ferramenta ICHIKAWA, foi realizado o alinhamento dos braços das castanhas no pré-conformador, como mostra a figura a seguir.

14 - Base Fixadoras das castanhas do Pré-conformador de carc desalinhadas.

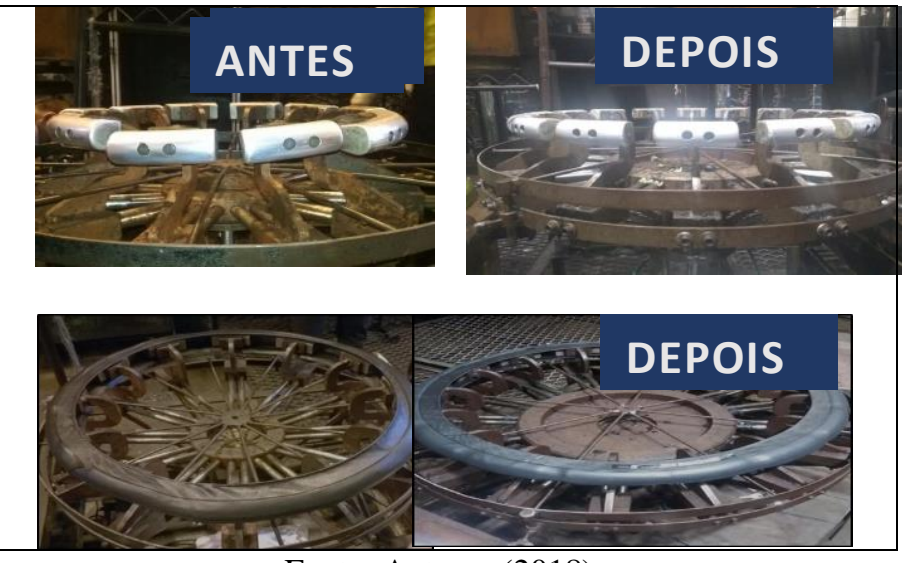

Fonte: Autores (2018).

15.Guia do Talão da confeccionadora desalinhado/ Empenar

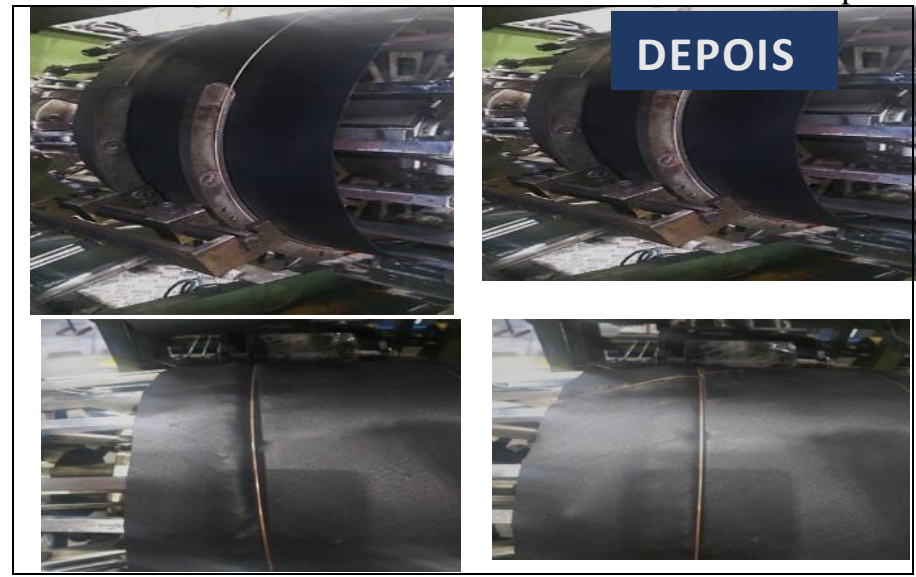

Fonte: Autores (2018)

16 - Instalação de reguladores de pressão ( manômetros ) par pre-conformador

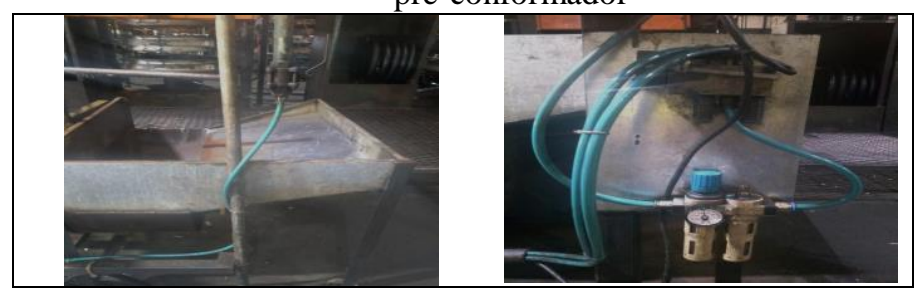

Fonte: Autores (2018).

\section{CONCLUSÃO}

Com a presente pesquisa foi possível identificar que o problema do fenômeno de talão mole ocorria em decorrência de um desalinhamento (altura e largura), nas bases onde são fixadas as castanhas. Com a análise do processo de pré - conformação também foi possível perceber que havia uma falta de reguladores para fixar a regulagem de acomodação da carcaça, pois, não havia (nesta máquina) uma forma de pressão ideal para cada modelo de fabricação do pneu. No decorrer deste trabalho, notou-se que o Guia do Talão também se encontrava
Desalinhado-Empenado. Dessa forma, foram realizados os Alinhamentos dos Braços das Castanhas com o objetivo não haver um deslocamento do Talão no momento da Préconformação garantindo pleno funcionamento e produtividade eficaz. Também foi realizado a Instalação de um Manômetro no pré conformador para garantir uma pressão padrão para todos os modelos de pneus. Também foi analisado e realizado o Alinhamento do Guia do Talão (imã) para garantir a centralização do talão no canal do tambor da confeccionadora (máquina). No processo de melhorias também foi incluído uma lista de checagem-(check-list) em cada setor para garantir que no início de cada turno o funcionário realizasse essa análise e assim se certificasse que a máquina e os materiais estivessem em perfeitas condições e prontas para seu funcionamento. Portanto, com as melhorias implementadas pela empresa os problemas foram solucionados e os números na produção começaram a crescer e o desperdício de material diminuiu significativamente, sendo este um fator primordial para sua permanência no mercado.

\section{AGRADECIMENTOS}

Ao PPGEP/UFPA, Ao ITEGAM, e empresa Levorin pelo apoio a pesquisa.

\section{REFERÊNCIAS BIBLIOGRÁFICAS}

[1] WERLANG, R. B. e SILVEIRA, F. L. A física dos pneumáticos. Physics of tires. Rio Grande do Sul. 2013.

[2] INFOPNEUS. História do Pneu. Disponível em: . Acesso em: 08 ago. 2016 .

[3] PINHEIRO, Eduardo Gonçalves. Modelos numéricos aplicados à vulcanização de pneus. Dissertação de mestrado. Escola Politécnica da Universidade de São Paulo. Departamento de Engenharia mecânica: São Paulo, 2001

[4] GOODYEAR. New Goodyear Innovation Could Make Tire Pumps Obsolete. 2011. Disponível em: Acesso em: 26 ago. 2017.

[5] COSTA a, Argemiro. Dinâmica Veicular - Pneumáticos: Histórico - Introdução. Pós- Graduação - Escola de Engenharia Mauá, São Caetano do Sul, 2011.

[6] FIORI, J.L. (Org.). Estados e moedas no desenvolvimento das nações. Petrópolis, RJ: Vozes, 2000. p.287-326. (Coleção Zero à Esquerda).

[7] GARBIM. V.J. Borrachas: tecnologia, características, compostos e aplicações. São Leopoldo: Editora Publit, 2012.

[8] LEVORIN, PNEUS. Histórico Atualizado em 2018 , https://www.levorin.com.br/

[9] RODRIGUES, M.R.P. Caracterização do resíduo da borracha de pneus inservíveis em compostos aplicáveis na construção civil. Tese em defesa do título de Doutor - Escola de Engenharia de São Carlos da Universidade de São Paulo, São Carlos, 2008.

[9] CHIAVENATO, Idalberto. Gestão de Pessoas . $3^{\mathrm{a}}$ ed. p..62 editora Elsevier/2014-RJ.

[10] CHIAVENATO, Idalberto. Gestão de Marketing. 2. ed. São Paulo: Elsevier, 2004. 